\title{
Defining infections in international travellers through the GeoSentinel surveillance network
}

\author{
Joseph Torresi and Karin Leder
}

Abstract | International travellers are often exposed to a wide range of infections, most of which are a reflection of common diseases in the destination country. The consequences of acquiring such infections are serious and can be associated with substantial morbidity and mortality. Attempting to define the range of infections and the risk factors that are associated with acquiring them during travel to different regions worldwide will provide an evidence base for the development and implementation of effective preventative interventions. This Science and Society article focuses on the valuable function served by the GeoSentinel surveillance network in defining the range of infections in travellers.

The ease with which individuals can undertake international travel has exposed large populations of travellers to a wide range of exotic infections. Air travel has resulted in a vast increase in trips from the developed to the developing world over the past decade. Visits from developed countries to Africa, the Americas and Asia increased by over $60 \%$ between 2000 and 2007 and are predicted to continue to increase by approximately $6 \%$ per year. Each year, over 100 million travellers from non-tropical regions will visit a developing country (see World Tourism Organization Facts and Figures), with up to half of these travellers developing a health problem abroad. Many of these travellers will become symptomatic during their trip, and in some instances they will carry infections such as measles, influenza and dengue fever back to their country of origin, potentially resulting in local epidemics of infection ${ }^{1}$. In addition, travellers may develop potentially life-threatening illnesses, such as malaria, while abroad, resulting in substantial morbidity and sometimes death ${ }^{2,3}$.

An accurate knowledge of the health problems that are faced by international travellers in different geographical destinations would provide a robust evidence base for physicians to use to deliver effective preventative advice, vaccinations and prophylactic medications to travellers ${ }^{4}$. However, our understanding of the range and frequency of infectious diseases in travellers is based primarily on several well-conducted studies that now date back over three decades ${ }^{5-10}$. More recent reports reflect the experience of single institutions or regions only, and differences in the study designs and research methodologies that were used to describe the burden of illness among travellers have complicated comparisons between studies.

In order to develop a more comprehensive and representative evidence base for the development of optimal preventative strategies and guidelines for international travellers, an accurate measure of the incidence of health problems among travellers is essential. The best available approximations of attack rates for various illnesses in international travellers, including infections that are preventable with the use of vaccines, have come from several disparate studies $^{4,11-18}$. These estimates are useful but do not reflect attack rates of illnesses according to the specific destinations visited, nor do they account for changes in illness risks over time. Detailed, up-to-date information could perhaps best be gained from large multi-centre prospective cohort studies, but such studies are difficult to perform, are extremely costly and must be repeated frequently if disease trends are to be followed ${ }^{19-24}$. An alternative approach is to analyse multi-centre data on the illnesses that are acquired by a broad range of travellers who are visiting regions on all continents, such as the data that are collected by international surveillance networks like the GeoSentinel network ${ }^{25}$ and TropNetEurop ${ }^{26}$. There are several differences between these two networks; most notably, the focus of TropNet is on Europe and the diagnostic categories are restricted to malaria ${ }^{2,27,28}$, dengue fever ${ }^{23,29}$ and $\underline{\text { schistosomiasis }}^{30}$, whereas GeoSentinel is global and collects data on a wider range of diseases. This Science and Society article focuses solely on the experience of the GeoSentinel network and reviews the main findings of several key studies that have contributed to defining the range of infections in international travellers. An indepth discussion of the methodologies that are used in GeoSentinel studies, and their associated limitations, has been recently published $^{31}$. This Science and Society article provides a complementary guide to understanding the research that is carried out by the GeoSentinel network.

\section{GeoSentinel surveillance network}

The GeoSentinel Surveillance network was established in 1995 through a collaborative agreement between the International Society of Travel Medicine (ISTM) and the $\mathrm{CDC}^{25}$. The principle objective of the GeoSentinel network was to develop a system for global surveillance in order to examine the spread of infectious diseases across international borders.

GeoSentinel sites are clinics that specialize in the field of travel and tropical medicine and that are widely dispersed on six continents (FIG. 1a). Individual sites are recruited on the basis of their training, experience and publications in travel or tropical medicine. The nature of the patients who are seen at GeoSentinel sites is a reflection of the specialist nature of the contributing clinics. Travellers reporting to GeoSentinel sites are seen either during travel or after their return home, and sites contribute clinician-based sentinel surveillance information. In addition, many sites manage health issues and infections in immigrants and refugees. The data are collected at individual sites and then sent to a central database at the CDC in Atlanta, USA (FIG. 1b). The patient's reason for travel (for example immigration, tourism, business, study or education, and visiting friends and relatives) is recorded, and the separation of travellers into categories on this basis has made it possible to carry out detailed analyses of the potential health problems that are faced by travellers who undertake different practices and face varied exposures while abroad.

Patient diagnoses are either confirmed in the laboratory, using the best reference diagnostics that are available to each site, or based on clinical criteria to provide probable diagnoses. For analytical purposes, confirmed versus probable categories can be readily separated if necessary. Diagnoses are recorded using a standardized list of more than 500 
a

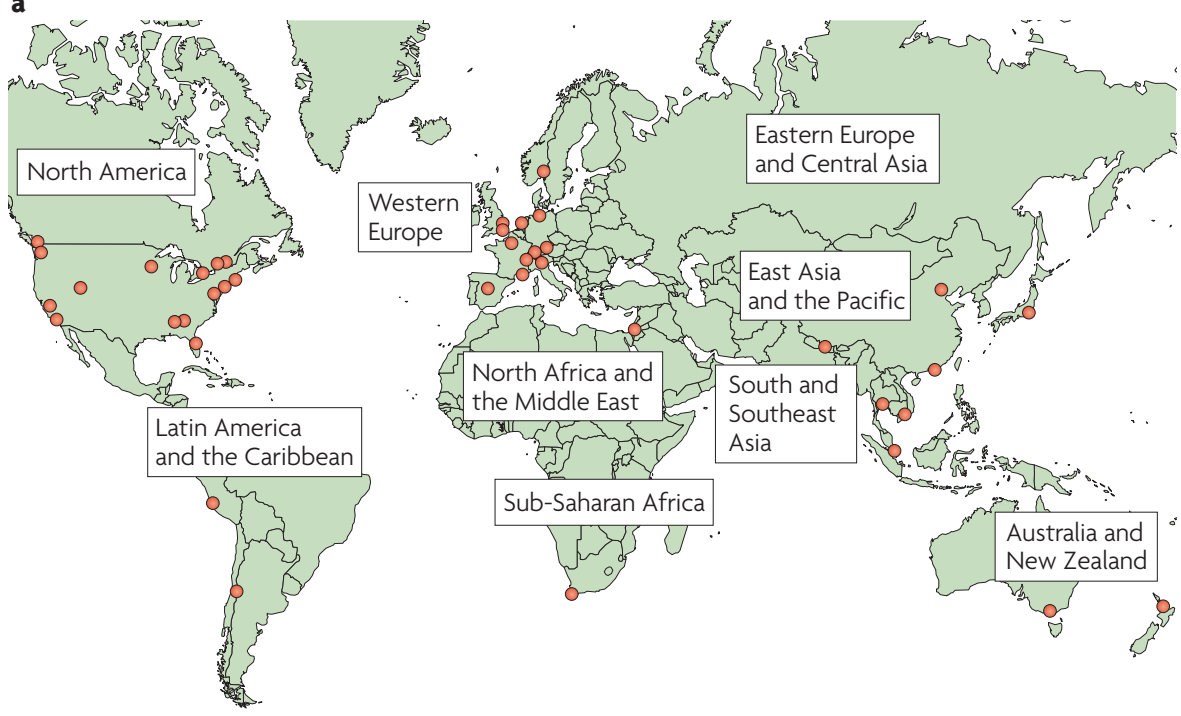

b

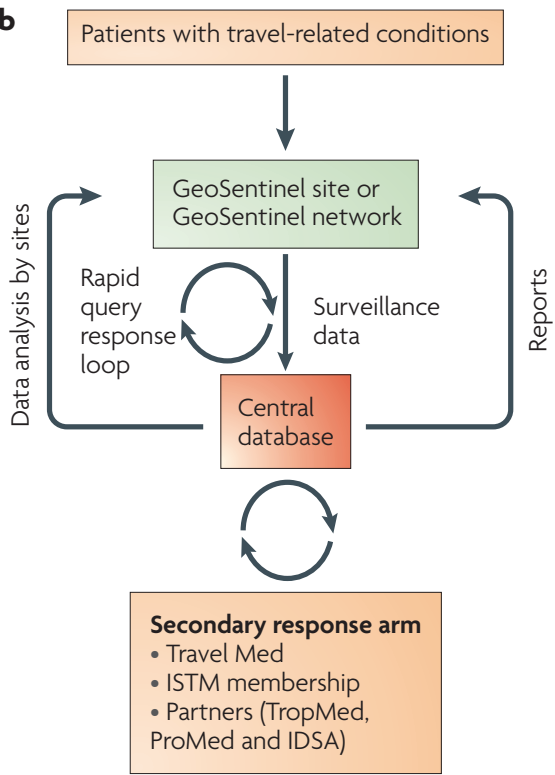

Figure 1 | GeoSentinel network and reporting structure. a | The global distribution of GeoSentinel sites, shown as orange circles. $\mathbf{b} \mid$ A schematic representation of the reporting structure of the GeoSentinel network. Data are collected at individual sites from patients with a travel-associated illness who present to a GeoSentinel clinic, and they are sent to the central database (which is maintained by the International Society of Travel Medicine (ISTM) at the CDC, Atlanta, USA) using a web-based reporting system. Quarterly reports are generated centrally, using collected data, and circulated back to GeoSentinel sites. Rare and alarming reports (such as avian influenza, severe acute respiratory syndrome (SARS) and haemorrhagic fever) trigger a rapid query response that is sent to the reporting site for further clarification and to all sites to notify them of such an event. The data are also made available to GeoSentinel sites to conduct research but only following a stringent project application process. Finally, GeoSentinel provides reports based on travel-associated illness and events data collected through the network to third-party groups such as the Australian College of Tropical Medicine (TropMed), ISTM, the Program for Monitoring Emerging Diseases (ProMED) and the Infectious Diseases Society of America (IDSA). Part $\mathbf{b}$ is modified, with permission, from http://www.istm.org/geosentinel/surveill.html @ (2008) GeoSentinel. diagnostic codes that are also divided into 21 general diagnosis groups ${ }^{25,32}$. For cases in which a specific etiological diagnosis cannot be made, the patient is assigned a code denoting a syndromic diagnosis.

The GeoSentinel database has proved to be an invaluable resource to study the range of infections that are acquired by international travellers. The size of the patient pool and the diverse global distribution of sites provide a useful sample for determining odds ratios, rate ratios or proportionate morbidities of acquiring infections according to travel destination and reason for travel $\mathrm{l}^{15,32-36}$ and can also reflect changes in proportional morbidity over time $\mathrm{e}^{37}$.

Recently, a comprehensive analysis of the GeoSentinel data collected thus far was reported $^{32}$, forming the largest multi-centre analysis of its type to date. This study provided a useful measure of the proportionate morbidities of infectious diseases acquired according to travel destination (FIG. 2a). Over 17,000 travellers with exposures in 230 countries and who presented to GeoSentinel sites located in 13 countries were included. Two-thirds of all diagnoses in returned travellers fell into four main syndrome categories: systemic febrile illness, acute diarrhoea, dermatological disorders and chronic diarrhoea. Malaria, dengue fever, Campylobacter infection, giardiasis and intestinal nematode infections were among the most commonly identified specific diagnoses. By examining the proportionate morbidities for both syndromic and specific diagnoses that were stratified according to region of travel, it was possible to develop a comprehensive profile of the infections that are encountered by international travellers.

Analyses of GeoSentinel data can therefore provide travel health practitioners with a useful resource to assist in formulating better targeted pre-travel intervention strategies and can also help to guide management of the ill returned traveller.

\section{Infectious disease case studies}

Prioritizing health issues in travellers and more detailed analyses of the factors associated with the acquisition of specific infections are important for assessing individual risks. Accordingly, the remainder of this article focuses on the specific findings of some of the key studies that were performed by the GeoSentinel network, to highlight how we can enhance our knowledge of the comparative risks that are associated with factors such as the type of traveller and the geographical region visited.

Fever in travellers. The cause of fever in returned travellers has been an area of intense interest and research in travel medicine. Recently, the GeoSentinel network performed an in-depth analysis of the infections that are associated with febrile illnesses in travellers ${ }^{36}$. Almost 25,000 travellers were included from a total of almost 55,000 reports collected from 31 GeoSentinel sites worldwide. Of the study participants who had a systemic febrile illness, the most common aetiology was malaria, accounting for $59 \%$ of all diagnoses. Other common diagnoses were acute diarrhoeal illnesses, respiratory tract infections (including influenza, pneumonia, bronchitis and tonsillitis), dengue fever, rickettsial infections (with tickborne spotted fevers accounting for $75 \%$ of rickettsial infections) and typhoid fever. A regional analysis provided a useful guide of the proportionate morbidities of these infections according to the region of travel (FIG. 2b). Malaria accounted for most febrile 
a
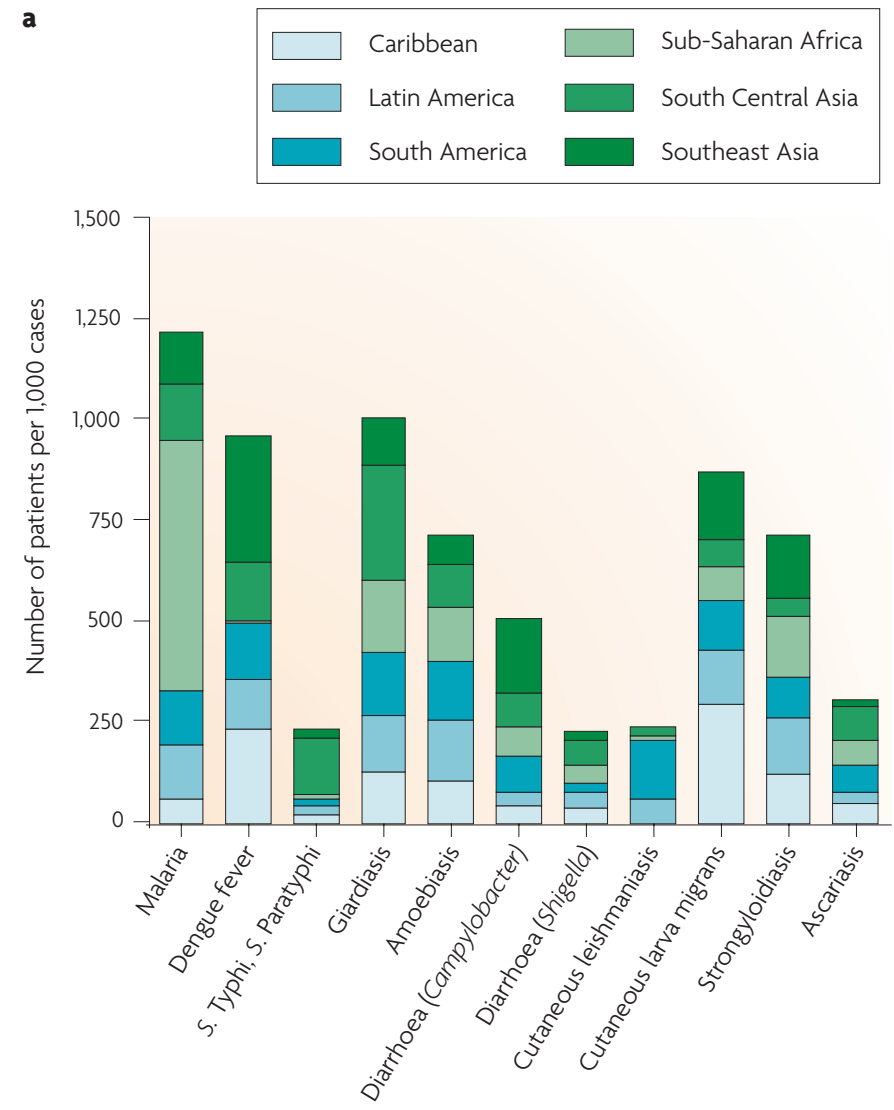

Figure 2 | Common diseases in travellers reporting to the GeoSentinel network. a | The proportionate morbidities of the common infections in international travellers that were reported to the GeoSentinel network. The proportionate morbidity is the number of patients with a diagnosis, or group of diagnoses, as a proportion of all ill travellers in the population studied. The data were collected at individual sites and then sent to a central database b
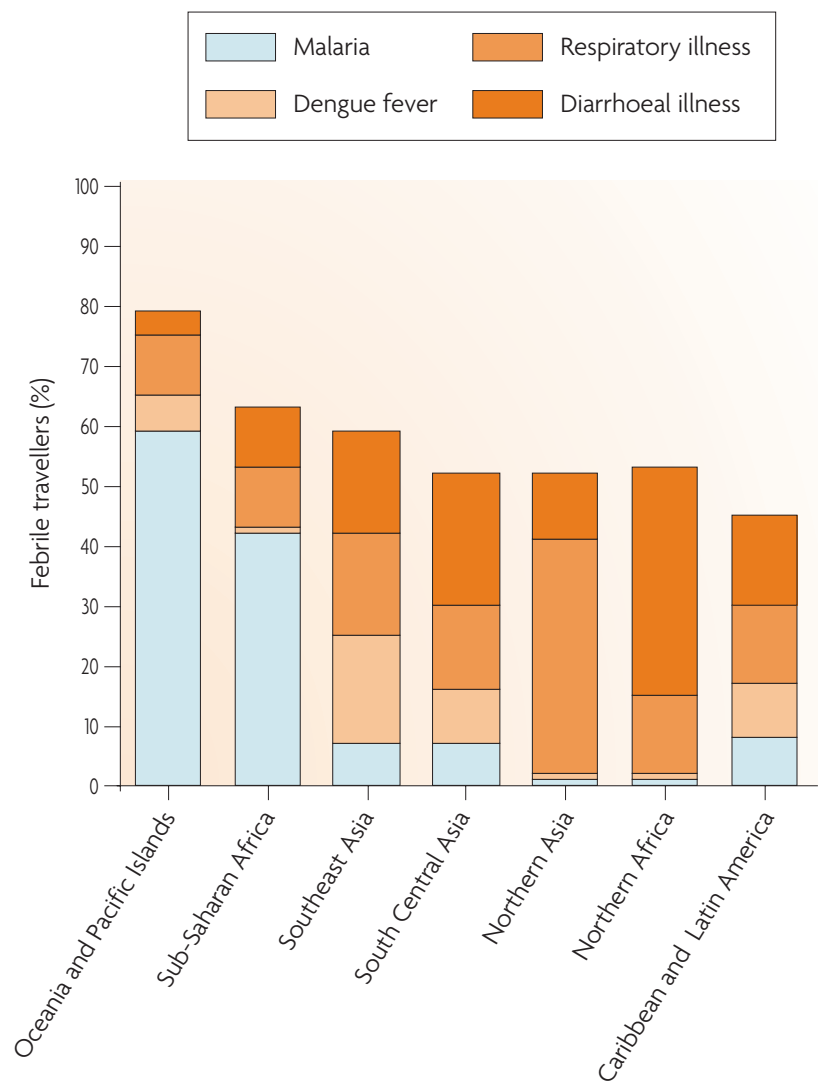

that is maintained by the International Society for Travel Medicine at the CDC in Atlanta, USA. $\mathbf{b}$ |The proportion of febrile travellers that were diagnosed with the more common infectious diseases, according to the region of travel. S. Typhi, Salmonella enterica subsp. enterica serovar Typhi; S. Paratyphi, Salmonella enterica subsp. enterica serovar Paratyphi. Part a data from REF. 32. Part b data from REF. 36. infections in travellers to Oceania and subSaharan Africa. By contrast, dengue fever was more frequent than malaria in travellers to Southeast Asia, south Central Asia, and the Caribbean and Latin America. Travel to Africa was more likely to be associated with acquiring malaria than dengue fever. Overall, diseases that can be prevented by vaccination (including hepatitis $A$ and $B$, influenza $A$ and $B$, meningococcal meningitis, pneumococcal infection, Haemophilus influenzae infection, measles, mumps, rubella, pertussis, tick-borne encephalitis, varicella (chicken pox) and typhoid fever, which is the result of Salmonella enterica subsp. enterica serovar Typhi infection) accounted for only $3 \%$ of all causes of febrile illnesses in travellers, but $60 \%$ of travellers with these infections required hospitalization. Estimates of the beneficial impact of pre-travel vaccination against infections such as influenza, hepatitis A and B, typhoid fever, yellow fever and Japanese encephalitis suggest that effective pre-travel vaccination would result in a substantial reduction in the morbidity and mortality from these diseases $^{4}$. This, together with a more accurate knowledge of the proportionate morbidity of acquiring infections in different geographical regions, argues strongly for the provision of vaccination before travel to high-risk destinations.

\section{Malaria in travellers. As a consequence} of travel to malaria-endemic countries, approximately 30,000 cases of travelassociated malaria are reported each year ${ }^{38}$. An accurate knowledge of the likelihood of acquiring malaria for each region of travel and the identification of risk factors that are associated with the development of severe malaria are paramount to effectively targeting preventative strategies for the disease. However, data from comprehensive comparative analyses of large numbers of travellers who have acquired malaria after travelling to diverse destinations have been lacking.
In a study involving over 1,100 travellers who acquired malaria over a 5-year period, the GeoSentinel network provided new insights into the travel characteristics that are associated with malaria acquisition $^{3}$. Plasmodium falciparum malaria accounted for $60 \%$ of all diagnoses, whereas Plasmodium vivax malaria was diagnosed in $24 \%$. Five percent of travellers with malaria had travelled for 1 week or less and $32 \%$ had travelled for 1-4 weeks, demonstrating that even travel of short duration can be associated with the acquisition of malaria. The disease was also more frequent in individuals travelling to visit friends and relatives than in other groups of travellers, highlighting this group as one requiring more intensive efforts in malaria prevention. Death due to malaria was infrequent (occurring in only $0.2 \%$ of the malaria sufferers who reported to GeoSentinel), but cerebral malaria occurred in $2.4 \%$ of individuals with a P. falciparum infection and severe complicated noncerebral malaria occurred in $1.4 \%$ of all 
a

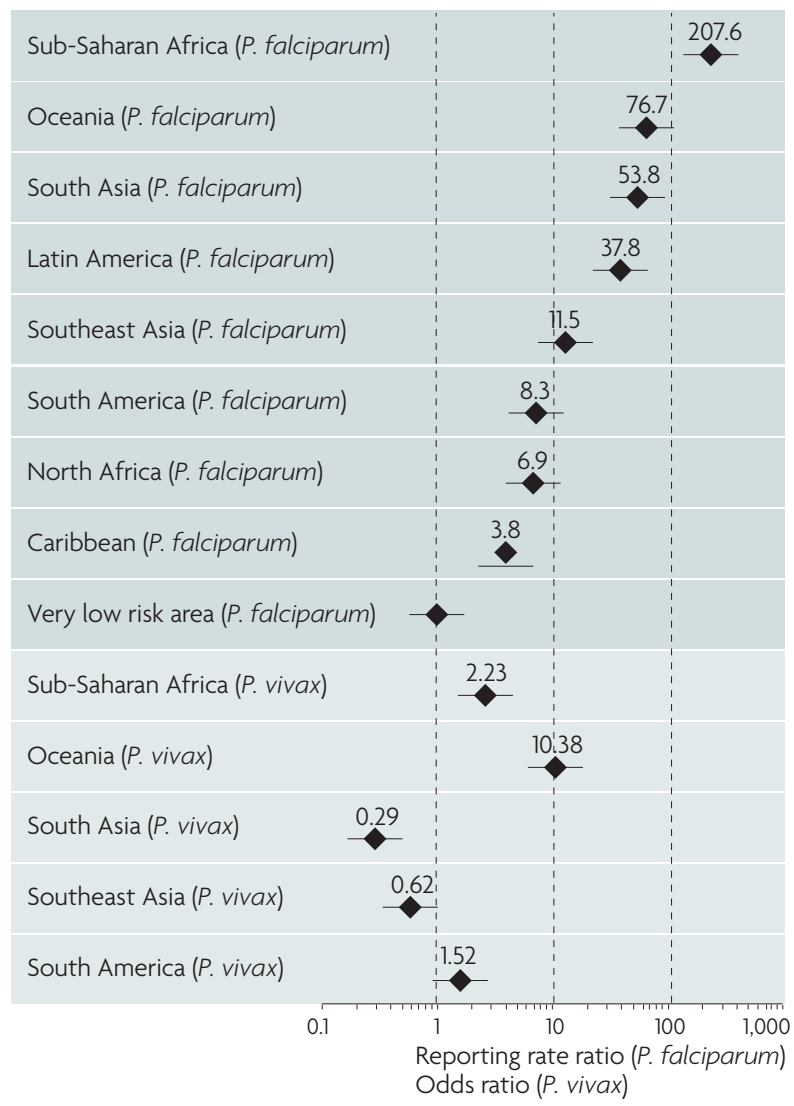

Figure 3 | Malaria in travellers reporting to the GeoSentinel network. a | The reporting rate ratios of Plasmodium falciparum malaria and odds ratios of Plasmodium vivax malaria, according to the region of travel. Reporting rate ratios were estimated as the number of patients presenting to GeoSentinel clinics who had a diagnosis of P. falciparum malaria and had travelled to the region divided by the number of tourist arrivals to the region

b

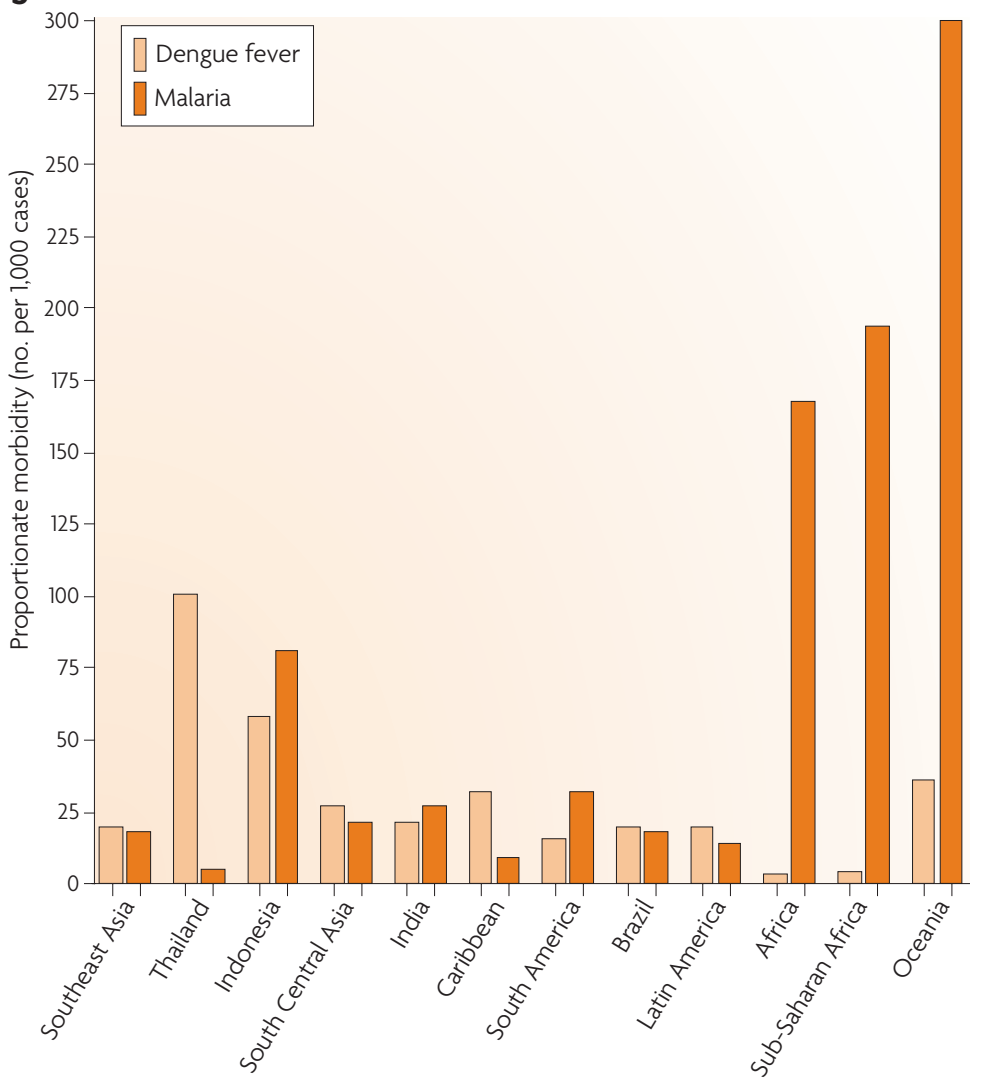

(according to data from the World Travel Organisation), calculated per ten million travellers. Odds ratios were calculated as the number of final diagnoses of $P$. vivax malaria in travellers to the region as a proportion of all patients presenting to GeoSentinel who had travelled to that region. $\mathbf{b}$ |The proportionate morbidity for malaria compared with dengue fever, according to the region of travel. Part a data from REFS 3,34. Part $\mathbf{b}$ data from REF. 37. reported cases. Increasing age was also found to be associated with a greater likelihood of developing cerebral and severe complicated malaria $^{3,27}$. A graduated risk of acquiring P. falciparum malaria according to region of travel was calculated, with sub-Saharan Africa posing the greatest risk, followed by Oceania and South $\mathrm{Asia}^{3}$ (FIG. 3a).

A separate GeoSentinel study focused on the epidemiology, demographics and risk factors for the acquisition of $P$. vivax malaria in travellers ${ }^{34}$. Travel to Papua New Guinea or Oceania was up to ten times as likely to be associated with the acquisition of $P$. vivax malaria than recent travel to all other regions (FIG. 3a). Travel to Papua New Guinea compared with travel elsewhere was also the only factor to be significantly associated with a relapse of $P$. vivax malaria after completion of treatment ${ }^{34}$. These studies provide a graduated profile of malaria risk by geographical destination and identify factors that are potentially associated with a poor clinical outcome. Information of this sort will assist practitioners in delivering effective preventative measures to travellers.

Dengue fever in travellers. The dramatic expansion of dengue fever throughout Southeast Asia, the Pacific region, the Caribbean and Latin America has led to over 100 million cases of dengue fever, including 250,000 cases of dengue haemorrhagic fever with over 20,000 associated deaths annually ${ }^{39-41}$. The increasing ease of travel to dengue-endemic regions has been accompanied by the frequent occurrence of dengue fever in international travellers ${ }^{16,23,29,42-48}$. Dengue fever is among the most common reasons for hospitalization of returned travellers ${ }^{36}$ and can result in dengue haemorrhagic fever in a small proportion of cases $^{49}$. In several single-centre studies, dengue fever has emerged as the second most frequent cause of fever in travellers returning from the tropics, following malaria ${ }^{8,46,50,51}$. Most cases of dengue fever in travellers are acquired in Asia $^{23,47}$.

In a longitudinal study of data collected over a decade by the GeoSentinel surveillance network, the month-by-month proportionate morbidity from dengue fever was determined in 522 cases of dengue fever from a total of 24,920 ill returned travellers ${ }^{37}$. A seasonal pattern for the acquisition of dengue fever and changing trends in proportionate morbidity over time were observed for different regions, including Southeast Asia, south Central Asia, the Caribbean and South America. Most cases reported corresponded to known epidemics in Southeast Asia in 2002, south Central Asia in 2003 and south Central Asia and Indonesia in 2005. A more detailed analysis of the proportionate morbidity for dengue fever during the cumulative 1997-2006 period in Southeast Asia revealed a seasonal fluctuation, with the number of cases more than doubling 
between the months of June and July. Clearly, the season of travel must be taken into consideration when providing travellers with advice about the risks of acquiring this disease. The occurrence of dengue fever in travellers reflected the year-to-year variation in dengue fever prevalence in endemic populations in the destination countries, demonstrating that the risk of dengue fever for travellers mirrors the risk among local populations. Information about the occurrence of dengue fever in travellers returning from endemic regions can also complement local surveillance systems, potentially helping to predict the onset of outbreaks of dengue fever. Finally, this study also provided a useful comparison of the relative proportionate morbidities for malaria and dengue fever in the same regions of travel (FIG. 3b).

By uncovering the seasonality of dengue fever and a differential distribution of malaria and dengue fever in travellers according to region of travel, health care practitioners can formulate meaningful pre-travel strategies and facilitate the assessment of ill returned travellers. For example, travellers with a previous episode of dengue fever can be advised to avoid travel during periods of peak dengue fever transmission to reduce their risk of developing dengue haemorrhagic fever, whereas travellers to sub-Saharan Africa and Oceania require more concerted efforts in malaria prevention, according to the data.

\section{Gastrointestinal infection in travellers.}

Travellers' diarrhoea is the most common medical problem to be reported by travellers, with over $60 \%$ of those who visit tropical and subtropical regions developing diarrhoea ${ }^{5,52-57}$ The epidemiology and risk factors associated with travellers' diarrhoea have been described in several single-centre studies ${ }^{5,654,56-60}$, but the broader range of gastrointestinal infections that are acquired by travellers according to their travel destinations had been poorly described.

The GeoSentinel network has conducted a comprehensive analysis of bacterial, parasitic and viral gastrointestinal infections in travellers ${ }^{61,62}$. Regions were categorized into low, moderate, high and very high proportionate morbidity areas; travellers to regions of high or very high proportionate morbidity were 200 and 800 times more likely to acquire a gastrointestinal infection, respectively, than travellers to regions of low or moderate proportionate morbidity, such as North America or central, eastern and southern Europe. Diagnoses of parasitic versus bacterial infections were also reported, with Campylobacter, Salmonella

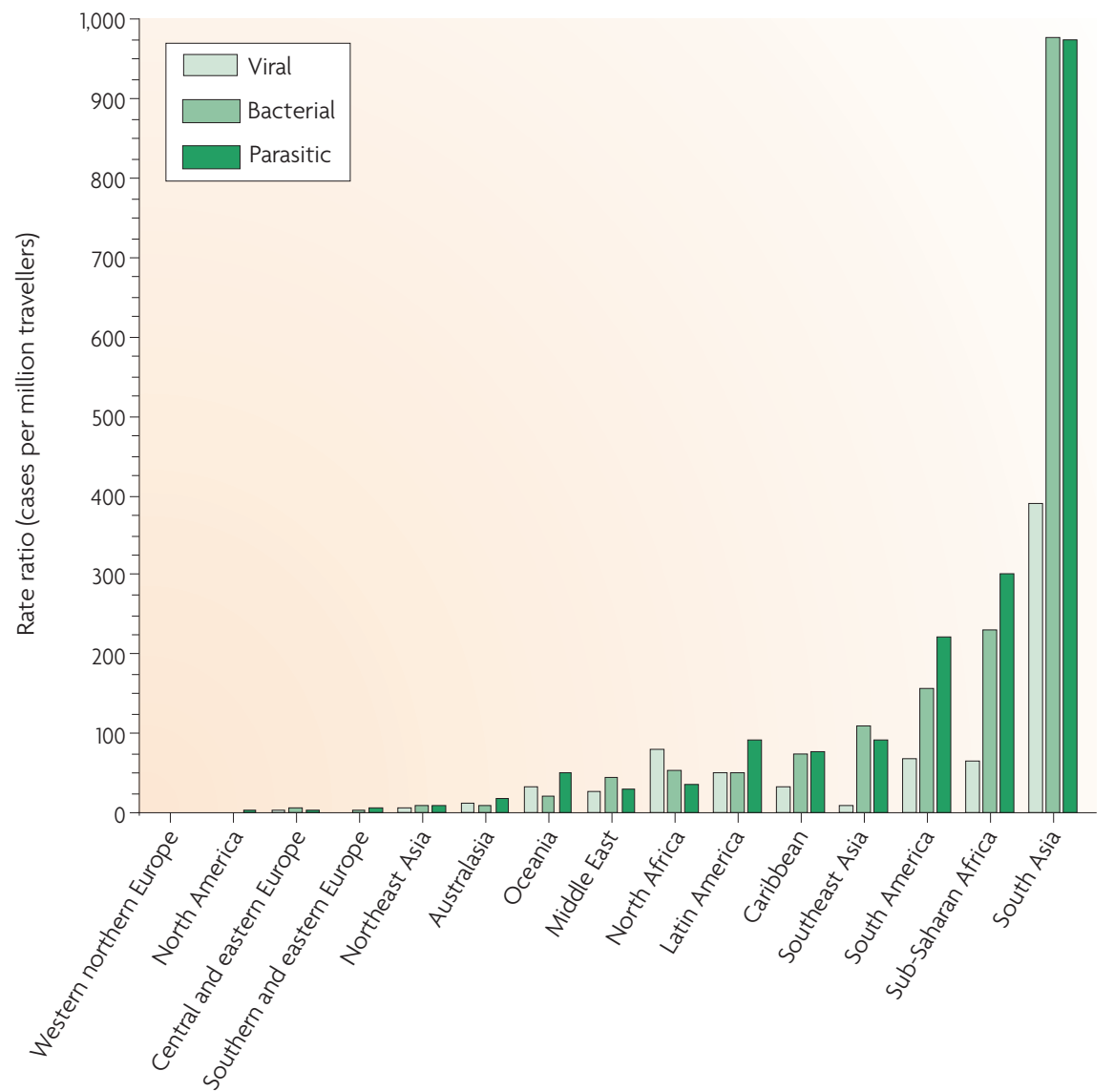

Figure 4 | The reporting rate ratios (in cases per million travellers) of acquiring viral, bacterial and parasitic gastrointestinal infections, according to the region of travel. Data from REF. 61 .

and Shigella being the most common bacterial pathogens and Giardia lamblia, Entamoeba histolytica and Strongyloides stercoralis being among the most frequent parasitic isolates $^{61}$ (FIG. 4). As a follow-up to this initial study, a comprehensive analysis of the specific microbial pathogens that are responsible for gastrointestinal infections in different regions of travel has recently been published by the GeoSentinel network ${ }^{62}$. This information serves not only to help give preventative advice before travel but also to direct the assessment, diagnosis and management of returned travellers with gastrointestinal disorders. For example, the data show that travellers to Southeast Asia should be provided with antimicrobials that will be effective against Campylobacter and giardiasis. Similarly, travellers returning from South Asia with a gastrointestinal illness should be carefully assessed for protozoal and bacterial infections, both of which occur frequently.

\section{Respiratory tract infections in travellers.} Several studies have reported that respiratory tract infections (RTIs) are among the most common causes of fever in travellers ${ }^{32,36,46,50,63}$, but few studies have characterized the range of upper and lower RTIs that occur in different categories of travellers or regions of travel; many studies have focused on determining the incidence of influenza alone ${ }^{64-70}$.

In one of its earliest studies, the GeoSentinel network examined the relative frequencies of upper and lower RTIs in travellers ${ }^{33}$. Not unexpectedly, travel during the winter of the destination country was associated with the acquisition of influenza, but travel during autumn was associated with an increased odds ratio for acquiring bronchitis and lower RTIs. This was of particular significance for travellers visiting friends and relatives, who were more likely to be diagnosed with influenza than other travellers, whereas pneumonia and bronchitis were comparatively less likely in business travellers than in other travellers. This report highlights the differences in the risks of acquiring RTIs, especially influenza, in different groups of travellers. Most current vaccination strategies against RTIs target influenza rather than other pathogens, but these findings can serve to guide diagnostic and management decisions in returned travellers presenting with 
an RTI. These findings were reinforced by another prospective analysis that reported an influenza attack rate among international travellers of $1.2 \%{ }^{64}$. The findings of the GeoSentinel study ${ }^{33}$ perhaps hold the greatest importance for influenza prevention among travellers. For example, the data show that it may be prudent to target travellers visiting the Northern Hemisphere between the months of December and February for vaccination to reduce their risks of acquiring influenza and of possibly carrying new strains of the virus back to their home countries.

\section{Limitations of GeoSentinel}

Despite the advantages of a standardized multi-centre data collection tool to help understand the relative risks of illness acquisition according to specific traveller and itinerary characteristics, GeoSentinel was not specifically designed as a research tool and there are a number of inherent limitations in the types of analyses that arise from the data collected through the network. Firstly, the data fields that are collected are limited - for example, data are not systematically collected on the prophylactic vaccines that are administered or the malaria chemoprophylaxis that is provided. Secondly, GeoSentinel sites are located primarily in academic centres, so it is likely that the patients referred to these centres are those with more severe or prolonged illnesses or those that have travelled to destinations that are perceived as being 'risky', and they will therefore not represent all travellers. In addition, there are selection and reporting biases in the types of patients and types of diagnoses that present at these specialized clinics. Non-specialized primarycare practices would presumably be likely to see more mild or self-limited conditions than the GeoSentinel clinics, and diseases with short incubation periods that manifest during travel (such as diarrhoea and influenza) are also likely to be under-represented. Thirdly, the patient intake at each site is likely to reflect local or national differences in the make-up of the travelling population and access to medical care. In addition, the type of accommodation, eating habits and other risk behaviours during travel may reflect the national and cultural background of the traveller, so the proportionate contribution of individual sites needs to be taken into account. These factors are important confounders that result in a notable selection bias for inclusion in the database, and this limits the ability to generalize the findings of analyses of GeoSentinel data. Fourthly, the geographical dispersion of GeoSentinel sites precludes centralized laboratory testing for all patients, so absolute uniformity in diagnostic criteria and recording across all GeoSentinel sites cannot be guaranteed.

The most important limitations, however, are that the data collected are a convenience sample of chosen GeoSentinel travel sites, so they do not depict all incidences of a disease that occur among travellers, and that information is only collected on travellers who seek medical care. Consequently, those who have remained well or who have had a shortlived illness during travel and who have not required medical follow-up will not be represented. GeoSentinel data can therefore not be used for incidence rate calculations or for the determination of absolute risks for the individual traveller.

\section{Conclusions}

Collaborative networks such as GeoSentinel use sentinel surveillance to monitor trends in imported infections. The data collected represent standardized longitudinal data from multiple global sites and can complement other research approaches to incrementally inform optimal pre- and post-travel disease management. Another important role of such networks is to facilitate communication between participating sites, which enables rapid dissemination of up-to-date information among clinical care providers. The studies performed by GeoSentinel have helped our understanding of the more common infections that are encountered by travellers. Other studies have focused on infections like schistosomiasis $^{71}$, dermatological conditions in travellers ${ }^{72}$, animal bites in travellers ${ }^{15}$ and the problems of specific groups of travellers such as those who are visiting family and relatives ${ }^{35}$. As the body of data collected by the GeoSentinel network continues to grow, the breadth of studies emerging from GeoSentinel will undoubtedly also grow to provide a useful source of information for the development and implementation of effective travel health guidelines.

Joseph Torresi is at the Department of Infectious Diseases and the Department of Medicine, Austin Hospital, PO Box 5555, Heidelberg, Victoria 3084, Australia.

Karin Leder is at the Victorian Infectious Diseases Service, Royal Melbourne Hospital, Grattan Street, Parkville, Victoria 3050, Australia and the Department of Epidemiology and Preventive Medicine, Monash University, Alfred Hospital, Melbourne, Victoria 3004, Australia.

Correspondence to J.T. e-mail: josepht@unimelb.edu.au doi: 10.1038/nrmicro2238 Published online 2 November 2009
WHO. Severe acute respiratory syndrome (SARS). Wkly Epidemiol. Rec. 78, 81-88 (2003).

2. Jelinek, T. et al. Imported falciparum malaria in Europe: sentinel surveillance data from the European Network on Surveillance of Imported Infectious Diseases. Clin. Infect. Dis. 34, 572-576 (2002). Leder, K. et al. Malaria in travelers: a review of the GeoSentinel surveillance network. Clin. Infect. Dis. 39, 1104-1112 (2004).

4. Steffen, R. \& Connor, B. A. Vaccines in travel health: from risk assessment to priorities. J. Travel Med. 12 26-35 (2005).

5. Steffen, R. Epidemiology of travellers' diarrhoea. Scand. J. Gastroenterol. Suppl. 84, 5-17 (1983).

6. Steffen, R. Epidemiologic studies of travelers' diarrhea, severe gastrointestinal infections, and cholera. Rev. Infect. Dis. 8 (Suppl. 2), S122-S130 (1986).

7. Reed, J. M., McIntosh, I. B. \& Powers, K. Travel illness and the family practitioner: a retrospective assessment of travel-induced illness in general practice and the effect of a travel illness clinic. J. Travel Med. 1, 192-198 (1994)

8. Doherty, J. F., Grant, A. D. \& Bryceson, A. D. Fever as the presenting complaint of travellers returning from the tropics. OJM 88, 271-288 (1995).

9. Ostroff, S. M. \& Kozarsky, P. Emerging infectious diseases and travel medicine. Infect. Dis. Clin. North Am. 12, 231-241 (1998).

10. Steffen, R., Rickenbach, M., Wilhelm, U., Helminger, A. ¿ Schar, M. Health problems after travel to developing countries. J. Infect. Dis. 156, 84-91 (1987).

11. Nothdurft, H. D. et al. The risk of acquiring hepatitis A and $B$ among travelers in selected Eastern and Southern Europe and non-European Mediterranean countries: review and consensus statement on hepatitis $A$ and $B$ vaccination. J. Travel Med. 14, 181-187 (2007)

12. Mutsch, M., Spicher, V. M., Gut, C. \& Steffen, R. Hepatitis A virus infections in travelers, 1988-2004. Clin. Infect. Dis. 42, 490-497 (2006).

13. Cetron, M. S. et al. Yellow fever vaccine. Recommendations of the Advisory Committee on Immunization Practices (ACIP), 2002. MMWR Recomm. Rep. 51, 1-11 (2002).

14. Monath, T. P. \& Cetron, M. S. Prevention of yellow fever in persons traveling to the tropics. Clin. Infect. Dis. 34, 1369-1378 (2002).

15. Gautret, P. et al. Animal-associated injuries and related diseases among returned travellers: a review of the GeoSentinel Surveillance Network. Vaccine 25, 2656-2663 (2007)

16. Cobelens, F. G. et al. Incidence and risk factors of probable dengue virus infection among Dutch travellers to Asia. Trop. Med. Int. Health 7, 331-338 (2002)

17. Cobelens, F. et al. Tuberculin skin test reactions by time of reading among Dutch travellers. Int. J. Tuberc. Lung Dis. 7, 758-763 (2003)

18. Cobelens, F. G. et al. Risk of infection with Mycobacterium tuberculosis in travellers to areas of high tuberculosis endemicity. Lancet 356, 461-465 (2000).

19. Hamer, D. H. \& Connor, B. A. Travel health knowledge, attitudes and practices among United States travelers. J. Travel Med. 11, 23-26 (2004).

20. Toovey, S., Jamieson, A. \& Holloway, M. Travelers' knowledge, attitudes and practices on the prevention of infectious diseases: results from a study at Johannesburg International Airport. J. Travel Med. 11, 16-22 (2004).

21. Van Herck, K. et al. Knowledge, attitudes and practices in travel-related infectious diseases: the European airport survey. J. Travel Med. 11, 3-8 (2004).

22. Wilder-Smith, A., Nor, K., Song, J. H., Chen, C. Y. \& Torresi, J. Travel health knowledge, attitudes and practice among Australasian travelers. J. Travel Med. 11, 9-15 (2004)

23. Jelinek, T. et al. Epidemiology and clinical features of imported dengue fever in Europe: sentinel surveillance data from TropNetEurop. Clin. Infect. Dis. 35, 1047-1052 (2002)

24. Jelinek, T., Nothdurft, H. D. \& Loscher, T. Malaria in nonimmune travelers: a synopsis of history, symptoms, and treatment in 160 patients. J. Travel Med. 1 , 199-202 (1994).

25. Freedman, D. O., Kozarsky, P. E., Weld, L. H. \& Cetron, M. S. GeoSentinel: the global emerging infections sentinel network of the International Society of Travel Medicine. J. Travel Med. 6, 94-98 (1999).

26. Jelinek, T. \& Myrvang, B. Surveillance of imported infectious diseases in Europe: report from the 4th TropNetEurop workshop. Acta Trop. 91, 47-51 (2004). 
27. Mühlberger, N. et al. Age as a risk factor for severe manifestations and fatal outcome of falciparum malaria in European patients: observations from TropNetEurop and SIMPID surveillance data. Clin. Infect. Dis. 36, 990-995 (2003).

28. Mühlberger, N. et al. Epidemiology and clinical features of vivax malaria imported to Europe: Sentinel surveillance data from TropNetEurop. Malar. J. 3, 5 (2004).

29. Jelinek, T., Dobler, G., Holscher, M., Loscher, T. \& Nothdruft, $\mathrm{H}$. Prevalence of infection with dengue virus among international travelers. Arch. Intern. Med. 157, 2367-2370 (1997).

30. Grobusch, M. P. et al. Imported schistosomiasis in Europe: sentinel surveillance data from TropNetEurop. J. Travel Med. 10, 164-169 (2003).

31. Leder, K., Wilson, M. E., Freedman, D. O. \& Torresi, J. A comparative analysis of methodological approaches used for estimating risk in travel medicine. J. Travel Med. 15, 263-272 (2008).

32. Freedman, D. O. et al. Spectrum of disease and relation to place of exposure in ill returned travelers. N. Engl. J. Med. 354, 119-130 (2006).

33. Leder, K. et al. Respiratory tract infections in travelers: a review of the GeoSentinel surveillance network. Clin Infect. Dis. 36, 399-406 (2003).

34. Elliott, J. H. et al. Imported Plasmodium vivax malaria: demographic and clinical features in non-immune travelers. J. Travel Med. 11, 213-219 (2004).

35. Leder, K. et al. Illness in travelers visiting friends and relatives: a review of the GeoSentinel surveillance network. Clin. Infect. Dis. 43, 1185-1193 (2006).

36. Wilson, M. E. et al. Fever in returned travelers: results from the GeoSentinel surveillance network. Clin. Infect. Dis. 44, 1560-1568 (2007).

37. Schwartz, E. et al. Seasonality, annual trends, and characteristics of dengue among ill returned travelers, 1997-2006. Emerg. Infect. Dis. 14, 1081-1088 (2008).

38. Loutan, L. Malaria: still a threat to travellers. Int J. Antimicrob. Agents 21, 158-163 (2003).

39. Mackenzie, J. S., Gubler, D. J. \& Petersen, L. R. Emerging flaviviruses: the spread and resurgence of Japanese encephalitis, West Nile and dengue viruses. Nature Med. 10, S98-S109 (2004).

40. Vasilakis, N. \& Weaver, S. C. The history and evolution of human gengue emergence. Adv. Virus Res. 72, 1-76 (2008).

41. Wilder-Smith, A. \& Gubler, D. J. Geographic expansion of dengue: the impact of international travel. Med. Clin. North Am. 92, 1377-1390 (2008).

42. Schwartz, E., Mendelson, E. \& Sidi, Y. Dengue fever among travelers. Am. J. Med. 101, 516-520 (1996).

43. Potasman, I., Srugo, I. \& Schartwz, E. Dengue seroconversion among Israeli travelers to tropical countries. Emerg. Infect. Dis. 5, 824-827 (1999).

44. Jelinek, T. Dengue fever in international travelers. Clin. Infect. Dis. 31, 144-147 (2000).
45. Schwartz, E. et al. Changing epidemiology of dengue fever in travelers to Thailand. Eur. J. Clin. Microbiol. Infect. Dis. 19, 784-786 (2000).

46. O’Brien, D., Tobin, S., Brown, G. V. \& Torresi, J. Fever in returned travelers: review of hospital admissions for a 3-year period. Clin. Infect. Dis. 33, 603-609 (2001).

47. Frank, C. et al. Increase in imported dengue, Germany, 2001-2002. Emerg. Infect. Dis. 10, 903-906 (2004)

48. CDC. Travel-associated dengue-United States, 2005. Morb. Mortal. Wkly Rep. 55, 700-702 (2006).

49. Sung, V., O’Brien, D. P., Matchett, M., Brown, G. V. \& Torresi, J. Dengue fever in travellers returning from South East Asia. J. Travel Med. 10, 208-213 (2003).

50. O’Brien, D., Leder, K., Matchett, E., Brown, G. \& Torresi, J. Illness in returned travelers and immigrants/ refugees: the 6-year experience of two Australian infectious diseases units. J. Travel Med. 13, 145-152 (2006).

51. Lindbäck, H. et al. Dengue fever in travelers to the tropics, 1998 and 1999. Emerg. Infect. Dis. 9, 438-442 (2003).

52. DuPont, H. L. \& Khan, F. M. Travelers' diarrhea: epidemiology, microbiology, prevention, and therapy. J. Travel Med. 1, 84-93 (1994).

53. Pitzinger, B., Steffen, R. \& Tschopp, A. Incidence and clinical features of traveler's diarrhea in infants and children. Pediatr. Infect. Dis. J. 10, 719-723 (1991).

54. Peltola, H., Kyronseppa, H. \& Holsa, P. Trips to the South - a health hazard. Morbidity of Finnish travellers. Scand. J. Infect. Dis. 15, 375-381 (1983).

55. Castelli, F., Pezzoli, C. \& Tomasoni, L. Epidemiology of travelers' diarrhea. J. Travel Med. 8, S26-S30 (2001).

56. Ericsson, C. D. \& DuPont, H. L. Travelers' diarrhea: approaches to prevention and treatment. Clin. Infect. Dis. 16, 616-624 (1993).

57. Kollaritsch, H. Traveller's diarrhea among Austrian tourists in warm climate countries: I. Epidemiology. Eur. J. Epidemiol. 5, 74-81 (1989).

58. von Sonnenburg, F. et al. Risk and aetiology of diarrhoea at various tourist destinations. Lancet 356 133-134 (2000).

59. Steffen, R. Epidemiology of traveler's diarrhea. Clin. Infect. Dis. 41, S536-S540 (2005).

60. Steffen, R. et al. Epidemiology of travelers' diarrhea: details of a global survey. J. Travel Med. 11 231-238 (2004)

61. Greenwood, Z. et al. Gastrointestinal infection among international travelers globally. J. Travel Med. 15, 221-228 (2008).

62. Swaminathan, A. et al. Pathogens and host risk factors associated with infectious gastrointestinal disease in returned international travelers. J. Infect. 59, 19-27 (2009).

63. Strickland, G. T. Fever in the returned traveler. Med. Clin. North Am. 76, 1375-1392 (1992).

64. Mutsch, M. et al. Influenza virus infection in travelers to tropical and subtropical countries. Clin. Infect. Dis. 40, 1282-1287 (2005).
65. Habib, N. A. \& Behrens, R. H. Respiratory infections in the traveler. Curr. Opin. Pulm. Med. 6, 246-249 (2000).

66. [No authors listed.] Influenza in travellers to Alaska, the Yukon Territory, and on west coast cruise ships, summer of 1999. Can. Commun. Dis. Rep. 25 137-139; discussion 139-141 (1999).

67. CDC. Influenza B virus outbreak in a cruise ship Northern Europe, 2000. JAMA 285, 1833-1834 (2001).

68. Balkhy, H. H., Memish, Z. A., Bafaqeer, S. \& Almuneef, M. A. Influenza a common viral infection among Hajj pilgrims: time for routine surveillance and vaccination J. Travel Med. 11, 82-86 (2004).

69. El Bashir, H. et al. Influenza among U.K. pilgrims to Haji, 2003. Emerg. Infect. Dis. 10, 1882-1883 (2004).

70. Marsden, A. G. Influenza outbreak related to air travel. Med. J. Aust. 179, 172-173 (2003).

71. Nicolls, D. J. et al. Characteristics of schistosomiasis in travelers reported to the GeoSentinel surveillance network 1997-2008. Am. J. Trop. Med. Hyg. 79 729-734 (2008).

72. Lederman, E. R. et al. Dermatologic conditions of the il returned traveler: an analysis from the GeoSentinel Surveillance Network. Int. J. Infect. Dis. 12, 593-602 (2008).

\section{Acknowledgements}

We thank D.O. Freedman and P.E. Kozarsky for helpful suggestions and review of the manuscript. GeoSentinel is supported by Cooperative Agreement U50/CCU412347 from the US Centers for Disease Control and Prevention and by annual funding from the International Society of Travel Medicine. GeoSentinel is made possible by the efforts and dedicated collaboration of our 48 sites in 23 countries.

DATABASES

CDC Diseases and Conditions Database http://www.cdc.gov/DiseasesConditions dengue fever | giardiasis | hepatitis | Japanese encephalitis | malaria |meningitis | pertussis | schistosomiasis | tick-borne encephalitis | typhoid fever | yellow fever Entrez Genome Project: http://www.ncbi.nlm.nih.gov/entrez/ query.fcgi? db=genomeprj

Entamoeba histolytica $\mid$ Giardia lamblia $\mid$ Haemophilus influenzae Plasmodium falciparum $\mid$ Plasmodium vivax $\mid$ Salmonella enterica subsp. enterica serovar Typh

FURTHER INFORMATION

CDC: http://www.cdc.gov

GeoSentinel: http://www.geosentinel.org

International Society of Travel Medicine: http://www.istm.org

TropNetEurop: http://www.tropnet.net

World Tourism Organization Facts and Figures:

http://www.world-tourism.org/facts/menu.htm

ALL LINKS ARE ACTIVE IN THE ONLINE PDF 